\title{
Civicae
}

\section{Brincadeiras: os benefícios do uso do brincar na educação infantil com crianças de 3 a 4 anos}

O ato de brincar é função fundamental para o desenvolvimento nos primeiros anos de vida. Nesse aspecto este estudo demonstra a importância do brincar no ensino-aprendizagem de crianças de 3 a 4 anos de idade, uma vez que o brincar possibilita um crescimento saudável à criança para que a mesma possa desenvolver todas as suas habilidades tornando-se um adulto bem resolvido e equilibrado psicologicamente, refletindo em seus aspectos físicos e emocionais. $O$ ato de brincar ainda possibilita que a criança compreenda e absorva o verdadeiro sentido de compartilhar, evitando que se torne um adulto egoísta e possessivo, seja materialmente ou sentimentalmente. $O$ brincar influência na autoestima, contribuindo também para formação de sua personalidade; pois toda brincadeira tem em si um significado que alcance e transmita seus objetivos. Desta forma, este trabalho se faz pertinente uma vez que se fundamenta na tese de que o brincar na educação infantil colabora para do desenvolvimento da criança. Buscou-se um levantamento bibliográfico, concernente a questão do brincar com o subsídio de diversas fontes, com consultas de obras respeitáveis e atualizadas.

Palavras-chave: Brincar; Ensino-Aprendizagem; Educação infantil.

\section{Play: the benefits of using play in early childhood education with children aged 3 to 4 years}

The act of playing is a fundamental function for development in the first years of life. In this aspect, this study demonstrates the importance of playing in the teaching-learning of children from 3 to 4 years of age, since playing allows a healthy growth for the child so that he can develop all his skills becoming a well-grown adult resolved and balanced psychologically, reflecting in its physical and emotional aspects. The act of playing still allows the child to understand and absorb the true sense of sharing, preventing him from becoming a selfish and possessive adult, whether materially or sentimentally. Playing influences self-esteem, also contributing to the formation of your personality; because every game has a meaning in it that reaches and conveys its objectives. In this way, this work becomes relevant since it is based on the thesis that playing in early childhood education contributes to the child's development. We searched for a bibliographic survey, concerning the question of playing with the subsidy of several sources, with consultations of respectable and updated works.

Keywords: Play; Teaching-Learning; Child education.

Topic: Pedagogia (Educação Criança e Adolescente) Reviewed anonymously in the process of blind peer.
Received: $\mathbf{2 0 / 1 1 / 2 0 1 9}$

Approved: $22 / 03 / 2020$
Izidorio Paz Fernandes Neto (iD

Faculdade Guaraí, Brasil

http://lattes.cnpq.br/7911321052215737

http://orcid.org/0000-0002-4868-1154

izidoriopaz@gmail.com

Denisy Alves Alencar

Faculdade Guaraí, Brasil

denisyalves123@gmail.com
Referencing this:

FERNANDES NETO, I. P.; ALENCAR, D. A.. Brincadeiras: os benefícios do uso do brincar na educação infantil com crianças de 3 a 4 anos. Justitia Liber, v.2, n.1, p.18-26, 2020. DOI: http://doi.org/10.6008/CBPC2674-6646.2020.001.0002 


\section{INTRODUÇÃO}

O presente estudo busca analisar e demonstrar os benefícios que a brincadeira concede para o conhecimento da criança, uma vez que o brincar pode contribuir para a formação de várias habilidades e potencializar as já existentes, tendo em vista a ampliação das palavras, do convívio social, da interação, vislumbrando o desenvolvimento como um todo.

Sabe-se que a criança tem necessidades e características completamente diferentes das pessoas já adultas, dessa forma a escola é fundamental e importante nesse sentido, onde muitas vezes a escola é o único lugar onde a criança encontra um espaço propício às brincadeiras que são trabalhadas em meio a situações de aprendizagem que por sua vez acabam se tornando relevantes, contribuindo para um desenvolvimento de maneira prazerosa e saudável.

A hora da brincadeira é de grande importância, já que permite que a criança trabalhe sua imaginação e sociabilidade, adquirindo habilidades fundamentais para seu desenvolvimento físico e mental, o ato de divertir-se permite que a criança explore o seu mundo interior, o universo ao seu redor, elevando o ato de brincar a outro nível de percepção, assim o ato de brincar passa a ser também um momento de descobertas e aprendizagem.

Dessa maneira é possível que, os educadores possam utilizar-se do método lúdico para enriquecer e facilitar o processo de ensino-aprendizagem na sala de aula, tornando o ato de aprender envolvente, prazeroso e bem mais significativo para seus alunos. Por essa razão, buscou-se evidenciar as práticas lúdicas como um potente mecanismo a ser utilizado pelos educadores, uma vez que é por meio da brincadeira que a criança reflete, organiza, desorganiza, constrói, destrói e reconstrói o seu mundo (SEBASTIANI, 2003).

Baseando-se na teoria de Vygotsky (1998), nota-se a relevância do ato de brincar como instrumento a ser utilizado a fim de que seja alcançado o pleno desenvolvimento infantil. Vygotsky (1998) ressalta que, "apesar do brinquedo não ser o aspecto predominante da infância, ele exerce uma enorme influência onde a criança aprende a atuar numa esfera cognitiva que depende de motivações internas" (REGO, 1995).

Revelando que no jogo a criança cria um momento imaginário, absorvendo elementos fornecidos pela interação e comunicação. Supondo que pode sim construir conhecimento por meio do brincar sendo que as brincadeiras deverão ser aplicadas de maneira pedagogicamente, uma vez que o brincar deixa de ser uma ação natural da infância para ser uma ação de grande importância da infância, pois não se trata apenas de brincar, mas de aprender quanto se brinca, tornando a aprendizagem um momento de prazer e descontração para a criança o que acaba por motivá-la a querer aprender mais.

Assim sendo, o presente trabalho ao tratar da importância do brincar na educação infantil visa demonstrar que a utilização de dinâmicas como jogos e brincadeiras, potencializa o ensino e contribui para o real aprendizado da criança, favorecendo o desenvolvimento de suas habilidades desde que o ato de brincar seja usado sobre uma visão pedagógica, refletindo no desenvolvimento cognitivo e social da criança, o que faz do ato de brincar um meio interessante e envolvente de promover a aprendizagem.

Para tanto, justifica-se a relevância deste trabalho por tratar de questões associadas ao ato de brincar 
e os benefícios do seu uso na Educação Infantil com crianças de 3 a 4 anos. Posto isso, averígua-se como imprescindível constituir profissionais qualificados para acolherem e envolverem as crianças nas mais diversas brincadeiras para esta faixa etária.

Na vida acadêmica, a pesquisa é um exercício que permite despertar o espírito de investigação diante dos trabalhos e problemas sugeridos ou propostos pelos professores e orientadores. Sendo assim, buscouse um levantamento bibliográfico, concernente a questão do brincar, com o subsídio de diversas fontes, com consultas de obras respeitáveis e atualizadas. A pesquisa foi exploratória, do tipo qualitativo-descritivo de cunho explicativo.

O estudo baseia-se em estudiosos que se dedicam a pesquisarem sobre a importância do lúdico para o desenvolvimento da criança, sendo destacados as teorias de Piaget, Vygotsky e outros que contribuíram de maneira significativa para essa visão de aprendizagem que se tem atualmente sobre a importância do lúdico.

\section{METODOLOGIA}

\section{Considerações relevantes acerca dos benefícios do brincar na educação infantil}

O ensino infantil é um tema amplamente discutido em quase todos os setores da sociedade. Ela é tema de trabalhos acadêmicos, campanhas políticas, de conversas informais nas escolas, entre outras repartições, desta forma compreender os meios para melhorar a Educação Infantil é otimizar o processo de ensino aprendizagem.

Vygotsky (1998), um dos mais importantes representantes da psicologia histórico-cultural, considerou em seus estudos que é durante as relações entre pessoas é que o sujeito se constrói, através das atividades próprias da natureza humana, assim as formas superiores de comportamento consciente são fruto das relações sociais que cada indivíduo cria com mundo exterior. Vygotsky (1998) defende que é na cultura que está a essência para o desenvolvimento humano. Uma vez que é da cultura que conseguimos absorver os sistemas simbólicos de representação da realidade, ou seja, é na cultura que se encontram os elementos essenciais para a construção dos valores, frisando a influência do brincar na construção do raciocino da criança o quanto o ato de brincar influencia na constituição do raciocínio da criança uma vez que quando a criança brinca essa manifesta seus sentidos visuais, auditivos, táteis, cognitivo e motor.

Segundo o Referencial Curricular Nacional da Educação Infantil (BRASIL, 1998):

\footnotetext{
O principal indicar da brincadeira, entre as crianças, é o papel que assumem enquanto brincam. Ao adotar outros papéis na brincadeira, as crianças agem frente à realidade de maneira não-literal.
}

Observa-se que por meio do brincar em que são trabalhadas atividade lúdicas a criança inicia no processo de contato com o mundo a sua volta e na construção das interações sociais, dessa forma quando a criança se envolve com atividade ela aprende como funciona o mundo a sua volta, pois ainda que de forma alusiva, a criança entra em outro mundo que se revela aos poucos, qual seja o mundo dos adultos.

$\mathrm{O}$ ato de brincar se revela de suma importância não apenas para o crescimento intelectual, mas 
também para o aprimoramento infantil e cultural da criança uma vez que brincar não se resume em um irrelevante momento de distração onde a criança vai ficar ociosa em um espaço com ou sem brinquedo, mas na verdade trata-se da oportunidade de transformar o brincar em um momento em que a criança pode aprender e ensinar. Os benefícios gerados estimulam o aprendizado contribuindo tanto para o desenvolvimento quanto para a construção de seu conhecimento, rompendo fronteiras e evoluindo seu raciocínio.

Vygotsky (1998), afirma que por meio de jogos infantis a criança sofre uma transformação uma vez que são beneficiados pelas circunstâncias dando oportunidade para que utilize a criatividade sendo dessa forma um dos motivos pelo quais os pedagogos vêm utilizando cada dia mais a brincadeira de maneira a contribuir para o ensino e aprendizagem tornando o brincar em uma ferramenta na educação e formação da criança.

O brincar pode ser aplicado em diversas categorias de vivencia que podem ser distinguidos entre brincar de faz-de-conta atividade fundamental onde, brincar com objetos que trabalhem a capacidade de construção e brincar jogos onde seja necessário a utilização de regras o uso deste tipo de materiais ou dos recursos utilizados trabalham a ludicidade ampliando os conhecimentos infantis, sendo o professor de fundamental relevância durante o processo de aprendizagem, uma vez que é ele o responsável por colaborar para que a criança alcance todo o conhecimento que seja possível por meio do brincar oferecendo as crianças brinquedos, jogos e histórias para sua imaginação, bem como organizando o espaço delimitando o tempo utilizado para brincar.

O professor deve ser o responsável por variar os assuntos das dinâmicas possibilitando que as crianças estabeleçam uma relação obedecendo o bom convívio social entre o mesmo favorecendo na interação durante a atividade proposta. $\mathrm{O}$ ato de brincar permite uma Pedagogia de afeto na escola. Permite um ato de amor, de afetividade cujo território é o dos sentimentos, das paixões, das emoções, por onde transitam medos, sofrimentos, interesses e alegrias (MALUF, 2003). Nesse contexto, é certo que o ensinar brincando é um fator de grande aproximação entre o professor e o aluno.

\section{DISCUSSÃO TEÓRICA}

\section{O brincar e seus benefícios nos primeiros anos da escolarização}

Observa-se que mesmo no âmbito familiar em casa com os pais, irmãos e os demais membros da família acontecem a interação social da criança com as pessoas a sua volta, pois é no contexto familiar que a criança aprende a brincar e desenvolver suas primeiras lembranças e emoções. Como as crianças vivem em um mundo de fantasias, onde a imaginação e o real se misturam e as emoções são transformadas em entendimento e esse entendimento é transformado em conhecimento.

Para Vygotsky (1998) o ato de brincar se faz importante uma vez que propicia abertura de novas sensações as quais conduzem a criança para seu imaginário e por consequência torna possível que a criança possa se desenvolver, pois brincando a criança trabalha seu imaginário tendo por consequência a criação do 
pensamento abstrato.

As crianças ao criarem uma história demonstram seus desejos e vontades. O faz de conta possibilita que a criança passeie entre o real e o imaginário, onde ela pode ser o que desejar ser, vivendo os papéis que desejar, vivendo onde desejar, resolver conflitos e a coordenar normas. O faz de conta é uma brincadeira em que será possibilitado a criança desenvolvimento da sua imaginação permitindo que seus pensamentos se realizem apenas pelo simples ato de imaginar.

Para Vygotsky (1998), o ato de brincar possibilita ao indivíduo inúmeras possibilidades de aprendizados que irão refletir no desenvolvimento pessoal. Dessa forma dentre as motivações que são recebidas é importante ressaltar que o desenvolvimento alcançado por meio da brincadeira vai muito além do desenvolvimento cognitivo, ou seja, a amplitude do desenvolvimento da criança é vasta, alcançando aspectos de âmbitos motores, de linguagem e socialização construindo identidade e vivências.

A Educação Infantil como sugere o próprio nome é uma educação voltada para a criança em fase inicial de formação. Segundo a Lei de Diretrizes e Bases da Educação Nacional - LDBEN, no 9.394 de 20 de dezembro de 1996, art. 29:

A educação infantil, primeira etapa da educação básica, tem como finalidade o desenvolvimento integral da criança até seis anos de idade, em seus aspectos físicos, psicológicos, intelectuais e sociais, completando a ação da família e da comunidade. (BRASIL, 1996)

Dando continuidade o art. 30 da mesma lei dispõe acerca da idade e o seu nível de acompanhamento escolar, onde crianças de até três anos terão sua educação oferecida em creches ou entidade equivalente e as crianças entre quatro e seis anos bem como para as crianças entre quatro e cinco anos será oferecida educação pré-escolar (BRASIL, 1996).

Sabemos que as crianças passam boa parte do tempo na escola dessa forma é interessante, que a mesma seja compreendida como um ambiente onde a criança além de conhecer e aprimorar seus potencias, possa brincar e tornar suas experiências mais significativas onde a metodologia aplicada é dinâmica proporcionando mais que conhecimento, que proporcione também experiências de vida.

Sebastiani (2003) relata que enquanto brinca a criança por meio da imaginação assume uma postura que no mundo real ainda não lhe é possível, praticando ações e atitudes que diferente dos adultos ela ainda não pode fazer pois a mesma age como se adulto fosse, essa atitude funciona como uma forma de compensação por ela ainda não poder fazer tudo que os adultos fazem. Como por exemplo, as crianças que se reúnem para brincar criando figuras do imaginário aparte do que elas vêm e ouvem sendo que no decorrer das brincadeiras possam lidar com os 'problemas' que podem surgi trabalhando o diálogo com os colegas buscando a solução dos problemas e assim adquirindo novos conhecimentos.

A filha que se veste com as roupas da mãe e usa seus sapatos e maquiagem tenta satisfazer seus desejos de ser e ter tudo o que sua mãe é e tem. O ditado popular que diz que os filhos são reflexo dos pais, talvez tenha explicação aqui uma vez que as crianças observam as suas voltas e buscam absorve o que elas expressão seja no modo de falar, andar, de se vestir e principalmente de se comporta.

Assim, observa-se que enquanto brinca a criança ampliar suas capacidades tais como atenção, 
memória, imaginação, imitação. Trabalhando suas capacidades de socialização que surgem da interação e o dinamismo de papeis, encargos e regras próprias do âmbito adulto.

Brincando, as crianças constroem seus próprios mundos e dos mesmos fazem o vínculo essencial para compreender o mundo do adulto, ressignificam e reelaboram acontecimentos que estruturam seus esquemas de vivência, sua diversidade de pensamentos e a gama diversidade de sentimentos. (MACEDO, 2004)

Nestas circunstâncias, brincar favorece para a autoestima da criança, não importando o grupo social em que esteja inserida.

\section{Métodos do desenvolvimento de Jean Piaget}

Piaget (1998), desenvolveu teorias diversas, uma delas conhecida como teoria congnitivodesenvolvimental que demonstra como as crianças desenvolvem seus conhecimentos, ou seja, a teoria formulada por Piaget (1998) busca verificar como se dá a evolução da inteligência humana, conferindo que o nascimento da sabedoria humana reside no próprio sujeito, onde o juízo objetivo não é inerente muito menos externo ao organismo, porém é essencialmente construído na interação homem-objeto.

Piaget (1998), através dessa teoria supracitada destaca que o crescimento da inteligência se dá devido á suposição de circunstâncias de relações correlatas entre o objeto a ser conhecido e o sujeito conhecedor. Esses elementos se complementam abrangendo processos complexos, espontâneos e contínuos entre si entrelaçados incluindo elementos complementares, como: amadurecimento, investigação, aprendizado coletivo e autocontrole do corpo ao meio.

A atuação proposta por Piaget (1998), constituí de subprocessos importantes, adaptação, assimilação e acomodação sendo que na adaptação o processo ocorre por meio das modificações constantes do indivíduo que decorrem de sua interação constante com o ambiente em que está inserido, ao passo que participa ativamente dos atos onde a criança adquire mentalmente dados sobre o ambiente social e físico convertendo o conhecimento adquirido em maneiras de agir sobre o meio sendo que, com a calmaria os novos conhecimentos tomam como base conhecimentos anteriores simples que servem de base para outras aprendizagens distintas, com a reorganização e transformação dos esquemas assimilatórios anteriores ajudando a criança em cada nova experiência.

Assim, aparte do momento em que o conhecimento assimilado transforma-se em uma nova forma de ação, inicia-se o processo de acomodação do organismo nos aspectos físicos e mentais e o ambiente no qual a criança está incorporada. Segundo Haydt, em sua obra Curso de Didática Geral (2011):

Na teoria piagetiana, a inteligência, a aprendizagem e o processo de construção do conhecimento aparecem inter-relacionadas e interdependentes. Estão vinculados aos processos de assimilação e acomodação e caminham sempre na direção de uma equilibração progressiva, isto é, tendem para um reajustamento ou reorganização, o que acarreta uma mudança no indivíduo. (MACEDO, 2004)

Segundo Piaget (1973) o processo de desenvolvimento se dá por meio de estágios, que são divididos da seguinte maneira: Sensório motor: Refere-se à fase inicial do desenvolvimento que vai do nascimento até os dois anos de idade. Este período é marcado pela evolução mental que é se dá com aptidão reflexiva da criança e pela inteligência prática. Neste período a aprendizagem da criança começa a se desenvolver, ou 
seja, a criança começa a ter experiência do seu próprio corpo. Neste período a criança começa a entende seus traços físicos, sendo de grande valia para que a criança construa sua identidade (PIAGET, 1973). Operatório Concreto: Este período que vai de dois aos onze anos de idade, divide-se em pré-operacional que ocorre entre os dois a sete anos, período caracterizado pela linguística prevalecendo a transdução, modelo antigo de raciocínio orientando-se de particular para particular. Sendo que modo intuitivo de raciocínio, o qual se inicia aos quatro anos de idade, desenvolvendo também o raciocínio lógico, tornando-se capaz de ordenar e classificar. Operatório Formal: Inicia-se aos onze e vai até aos quinze anos período onde a criança é competente de pensar logicamente ainda que este não seja real. Uma vez que este ainda sofre com os ajustes da realidade.

Todos estes métodos supracitados estão englobados na Base Nacional Comum Curricular, conhecida como BNCC, que foi criada recentemente para ampliar e normatizar o conjunto de aprendizagens essenciais que todos os alunos devem desenvolver ao longo das etapas e modalidade da Educação Básica no Brasil. Para tanto, a aposta da BNCC é que a ludicidade deve ser o ponto de partida dos currículos da Educação Infantil.

\section{Jogos: ensino-aprendizagem socializante}

O jogo é um exercício organizado por um sistema de normas que pode trabalhar tanto o físico quanto o mental e por ser uma atividade nata do ser humano que traz prazer e acaba sendo uma atividade lúdica, pois ao jogar faz-se isso pelo prazer que o ato de jogar proporciona. Acredita-se que ao utilizar o jogo o professor disponibiliza um espaço que possibilita aos alunos a criação e a interatividade onde o aluno participa ativamente do processo de ensino aprendizagem considerando as informações e o aprendizado já obtido aprimorando os valores já concebidos.

O mundo da criança é diferente do mundo do adulto, pois nele há encantamento e o faz de conta. É por meio de suas brincadeiras que a criança irá se conhecer e terá a oportunidade de se constituir socialmente. Ele poderá expressar as diferentes impressões vivenciadas em seu contexto familiar e social, por intermédio da espontaneidade do brincar. Para tanto, Duflo (1999) afirma que,

\footnotetext{
Não que antes (na Antiguidade) não se tivesse jamais falado sobre ele e que não houvesse nenhuma página dedicada ao assunto. Simplesmente o jogo era posto de lado, ao lado do divertimento e assimilado, por isso, às coisas que não têm verdadeira importância e às quais não devemos dar muita atenção.
}

Contudo, há muito tempo atrás o jogo era considerado uma espécie de descanso, e assim saiu por muito tempo da cena de importância. $\mathrm{O}$ ato da exclusão pode referir-se ao consenso de realçar as atividades relacionadas ao trabalho como superiores aos divertimentos, constituindo-se assim a oposição jogo/trabalho, não destinando muito tempo a isso.

Entretanto, ao passar do tempo às brincadeiras passaram a ser objeto de estudo realizado pelos teóricos que dedicaram suas pesquisas às representações mentais. Onde surgem então às contribuições de autores como Piaget, Vygotsky, Leontiev, Huizinga e outros que mostram a importância das brincadeiras no desenvolvimento da criança e nas aquisições de conhecimentos. As pesquisas desses pesquisadores influenciaram diretamente o campo educacional. 
Almeida (1978) afirma que, os jogos não devem ser fins, mas meios para atingir objetivos. Estes devem ser aplicados para o benefício educativos e de maneira correta. O Referencial Curricular Nacional para a Educação Infantil ressalta que,

\begin{abstract}
A brincadeira favorece a autoestima das crianças, auxiliando-as a superar progressivamente suas aquisições de forma criativa. Brincar contribui, assim, para a interiorização de determinados modelos de adultos, no âmbito de grupos sociais diversos. Essas significações atribuídas ao brincar transformam-no em um espaço singular de constituição infantil. (BRASIL, 1998)
\end{abstract}

As atividades lúdicas são indispensáveis para apreensão dos conhecimentos artísticos e estéticos, pois possibilita o desenvolvimento da percepção, imaginação, fantasia e dos sentimentos. Portanto, é nas brincadeiras que as crianças transformam os conhecimentos que já possuíam anteriormente em conceitos gerais com os quais brinca (BRASIL, 1998).

Na visão de Huizinga (1971), o jogo é um dos componentes que poderia explicar o homem em seu habitat nos tempos atuais. Para este autor, é no jogo e pelo jogo que a civilização surge e se desenvolve. Para ele o jogo não é um fenômeno puramente biológico, mas sim um fenômeno cultural, ou seja, é biológico e cultural. A atividade lúdica infantil é elementar, pois fornece informações importantes a respeito da criança: suas emoções, interação com o outro, o desempenho físico-motor, o nível linguístico, o estágio de seu desenvolvimento e sua formação moral.

Segundo Kishimoto (2003), o jogo vincula-se ao sonho, à imaginação, ao pensamento e ao símbolo. Sendo está uma proposta para a educação de crianças e educadores, com base no jogo e nas linguagens artísticas. A concepção de Kishimoto sobre o homem como ser simbólico, que se constrói coletivamente e cuja capacidade de pensar está ligada à capacidade de sonhar, imaginar e jogar com a realidade, é fundamental para propor uma nova "pedagogia da criança". Kishimoto vê o jogar como gênese da "metáfora" humana. Sendo aquilo que os torna realmente humanos. Para Kishimoto (2003),

A utilização do jogo potencializa a exploração e construção do conhecimento, por contar com a motivação interna, típica do lúdico, mas o trabalho pedagógico requer a oferta de estímulos externo e a influência de parceiros, bem como a sistematização de conceitos em outras situações que não jogos.

Quando a criança está jogando ela se sente desafiada a vencer, aprende a persistir, e é incentivada a questionar e a corrigir suas ações. Dessa forma, quando se tornar adulto terá persistência para alcançar seus objetivos e enfrentar os percalços que venham a surgir. O jogo é também um exercício de autonomia, pois há um contexto relacional; é um espaço possível em que algo pode acontecer com o outro, na relação. 0 jogo ensina a tomar decisões, a antecipar o que o adversário vai fazer e, neste sentido, jogar é aprender a pesquisar e tomar decisões. Portanto, é através do jogo, da brincadeira ou do brinquedo, que o docente observa o comportamento físico e mental das crianças, as características de sociabilidade proporcionadas pelo jogo, nas trocas, competições, atitudes, reações e emoções.

\title{
CONCLUSÕES
}

Este trabalho foi realizado sob o propósito de analisar mais afundo os benefícios do brincar no ensino aprendizagem na Educação Infantil nos anos iniciais, como o brincar e o lúdico atrai de forma significativa a 
atenção da criança, estimulando as mais variadas potencialidades seja no desenvolvimento social ou na própria construção do conhecimento, levando em consideração os níveis de dificuldades e os aspectos facilitadores que ocorrem dentro da dinâmica da educação que são inerente a prática de ensino.

Sendo assim, o brincar deve ser visto não como mera brincadeira, mas como uma ponte de ligação para que a criança alcance seus potenciais e habilidades no processo de ensino aprendizagem de maneira significativa e construtiva. Objetivando demonstrar à importância do tema, a pesquisa realizada proporcionou uma vasta experiência a respeito da Educação Infantil levando em conta as diferenças e as contribuições pelos métodos de ensino adotados no ato do brincar.

Contudo, é de grande importância garantir no âmbito escolar, tempo e espaço para desenvolver o brincar, mesmo que não haja quantidade e/ou variedade de materiais disponíveis, visto que o jogo simbólico acontece independentemente desses recursos, pois a criança transforma o significado das coisas de acordo com seus desejos.

Ao concluir este trabalho, pode-se afirmar que a pesquisa ampliou o conhecimento pedagógico, pois envolveu um tema de relevância para a futura profissão. Onde ensinar e aprender brincadeiras a crianças são processos complexos, e que professores e alunos devem ser sujeitos ativos na construção do conhecimento e nada melhor do que aliar habilidades, competências, recursos e técnicas de ensinos diversificados ao uso do lúdico para alcançar com êxito o propósito da educação, afinal de conta o conhecimento é o principal fator da inovação do ser humano, e cresce exponencialmente na medida em que é explorado.

\section{REFERÊNCIAS}

ALMEIDA, P. N.. Dinâmica lúdica jogos pedagógicos. São Paulo: Loyola, 1978.

BRASIL. Ministério da Educação e do Desporto. Secretaria de Educação Fundamental. Referencial curricular nacional para a educação infantil. Brasília: MEC, 1998.

BRASIL. Ministério da Educação e do Desporto. Lei de diretrizes e Bases da Educação Infantil (LDBEN), n. 9.394, de 20 dezembro de 1996. Estabelece as diretrizes e bases da Educação nacional. Brasília: DOU, 1996.

DUFLO, C.. O jogo de Pascal a Schiller. Porto Alegre: Artmed. 1999.

HAYDT. R. C. C.. Curso de Didática Geral. São Paulo: Ática, 2011.

HUIZINGA, J.. Homo Ludens: o jogo como elemento de cultura. São Paulo: Pespectiva, 1971.

KISHIMOTO, T. M.. Jogos Tradicionais Infantis. São Paulo: Fapesp, 2003.
MACEDO, L.. Faz-de-conta na escola: a importância do brincar. Revista Pátio: Educação Infantil, v.1, n.3, p.12, 2004.

MALUF, Â. C. M.. Brincar: Prazer e Aprendizado. Petrópolis, Rio de Janeiro: Vozes, 2003.

PIAGET, J.. A formação do símbolo na criança. 3 ed. Rio de Janeiro: Zahar, 1973.

PIAGET, J.. A psicologia da criança. Rio de Janeiro: Bertrand Brasil, 1998.

REGO, T. C.. Vygotsky: uma perspectiva histórica-política cultural da educação. 13 ed. Petrópolis: Vozes, 1995.

SEBASTIANI, M. T.. Fundamentos Teóricos e Metodológicos da Educação Infantil. Curitiba: IESDE, 2003.

VYGOTSKY, L. S.. A Formação Social da Mente. 6 ed. São Paulo: Martins Fontes, 1998.

A CBPC - Companhia Brasileira de Produção Científica (CNPJ: 11.221.422/0001-03) detém os direitos materiais desta publicação. Os direitos referem-se à publicação do trabalho em qualquer parte do mundo, incluindo os direitos às renovações, expansões e disseminações da contribuição, bem como outros direitos subsidiários. Todos os trabalhos publicados eletronicamente poderão posteriormente ser publicados em coletâneas impressas sob coordenação da Cognitionis Publishing, da Companhia Brasileira de Produção Científica e seus parceiros autorizados. Os (as) autores (as) preservam os direitos autorais, mas não têm permissão para a publicação da contribuição em outro meio, impresso ou digital, em português ou em tradução. 